\title{
EFECTO DEL PROCESO DE ELABORACIÓN DE LA CONSERVA "DESMENUZADO DE ANCHOVETA" (Engraulis ringens) SOBRE LOS ÁCIDOS GRASOS POLIINSATURADOS OMEGA 3
}

\author{
Effect of the preparation of canned "crumbled anchovy" (Engraulis ringens) on polyunsaturated \\ omega 3 fatty acids
}

Lenny R. Ordoñez ${ }^{1,2}$, Eloisa M. Hernández ${ }^{2,3}$

${ }^{1}$ Instituto Tecnológico de lta Producción del Perú, Lima-Perú.

${ }^{2}$ Facultad de Farmacia y Bioquímica. ${ }^{3}$ Instituto de Investigación en Química Biológica, Microbiología y Biotecnología "Marco Antonio Garrido Malo”, de la Facultad de Farmacia y Bioquímica. Universidad Nacional Mayor de San Marcos.

\section{RESUMEN}

La anchoveta (Engraulis ringens) es uno de los principales recursos pesqueros explotados en el Perú. Es rica fuente de proteínas de alto valor biológico y de ácidos grasos poliinsaturados omega-3: ácido eicosapentaenoico (EPA) y ácido docosahexaenoico (DHA). El objetivo fue determinar el efecto del proceso de elaboración de la conserva de "desmenuzado de anchoveta", con énfasis sobre los ácidos grasos poliinsaturados omega-3 y el contenido real de estos en la conserva. Se elaboró siguiendo la tecnología estandarizada por el Instituto Tecnológico de la Producción (ITP). Se evaluaron parámetros físico-químicos, microbiológicos y el perfil de ácidos grasos totales en la conserva mediante métodos validados del ITP y de la Administración de Alimentos y Drogas de Estados Unidos (FDA). Las cantidades encontradas de EPA (21,2\%) y de DHA (15,8\%) en filete crudo sin piel, disminuyeron en la precocción y en la esterilización de la conserva a $20,8 \%$ y $15,5 \%$, respectivamente. Los niveles de histamina (2,2 ppm), bases volátiles totales (9,34 mg\%) y la prueba de esterilidad, indicaron que la conserva "desmenuzado de anchoveta" es un producto inocuo. Se concluye que el proceso de elaboración de la conserva no afecta significativamente el contenido de ácidos grasos poliinsaturados omega-3.

Palabras clave: anchoveta, ácidos grasos omega-3, conserva de anchoveta .

\section{SUMMARY}

The anchoveta (Engraulis ringens) is a major fishery resources exploited in Peru. It is rich source of proteins of high biological value and polyunsaturated fatty acids omega-3: eicosapentaenoic acid (EPA) and docosahexaenoic acid (DHA). The objective was to determine the effect of the process of preparing the canned "crumbled anchovy" with emphasis on polyunsaturated omega-3 fatty acids_and true content of them in canning. It was developed following the standardized technology by the Institute of Production Technological (ITP). The chemical, microbiological and physical parameters of total fatty acids profile of canned were evaluated using validated methods by ITP and the Food and Drug Administration (FDA). The amounts of EPA (21,2\%) and DHA (15,8\%) in raw fillet without skin, decreased with pre-cooking and sterilizing canning to $20,8 \%$ and $15,5 \%$, respectively. Histamine levels (2,2 ppm), total volatile bases ( $9,34 \mathrm{mg} \%)$ and the sterility test, indicated that the canning "crumbled anchovy" is a safe product. It is concluded that_canning elaboration process not affect significantly the content of polyunsaturated fatty acids omega-3.

Keywords: anchovy, omega-3 fatty acids, canned anchovy.

\section{INTRODUCCIÓN}

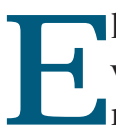

1 Perú es uno de los países con mayores volúmenes de extracción pesquera en el mundo, siendo la anchoveta, el principal recurso explotado para fabricación de harina y aceite para consumo humano indirecto destinado a mercados internacionales. Recientemente este recurso está siendo utilizado para elaborar conservas, productos curados y congelados ${ }^{(1)}$, diversificando su aprovechamiento para consumo humano directo.
La anchoveta es fuente de proteína de alta calidad, minerales (potasio, hierro, fósforo, calcio), vitaminas (A y D) y ácidos grasos poliinsaturados omega-3: eicosapentaenoico (EPA) y docosahexaenoico (DHA). Estos últimos, reconocidos por su actividad biológica en el desarrollo del sistema nervioso central, específicamente del cerebro, la función visual ${ }^{(2)}$ y en la salud cardiovascular ${ }^{(3)}$.

Sin embargo, en nuestro país, la incorporación de anchoveta en las dietas habituales es muy pobre. Por otro lado, la desnutrición crónica infantil aún afecta 
Tabla 1. Composición proximal de anchoveta en cuatro etapas del proceso de elaboración de la conserva "desmenuzado de anchoveta". *

\begin{tabular}{cccccc}
\hline $\begin{array}{c}\text { Etapa del } \\
\text { proceso }\end{array}$ & Producto & $\begin{array}{c}\text { Agua } \\
\mathbf{g} \%\end{array}$ & $\begin{array}{c}\text { Proteínas } \\
\mathbf{g} \%\end{array}$ & $\begin{array}{c}\text { Lípidos } \\
\mathbf{g} \%\end{array}$ & $\begin{array}{c}\text { Minerales } \\
\mathbf{g} \%\end{array}$ \\
\hline Recepción & $\begin{array}{c}\text { Anchoveta } \\
\text { entera cruda }\end{array}$ & $73,5 \pm 0,01$ & $18,4 \pm 0,1$ & $6,99 \pm 0,04$ & $1,33 \pm 0,04$ \\
$\begin{array}{c}\text { Eliminación } \\
\text { de la piel }\end{array}$ & $\begin{array}{c}\text { Filete crudo } \\
\text { sin piel }\end{array}$ & $76,9 \pm 0,06$ & $19,5 \pm 0,1$ & $2,10 \pm 0,01$ & $1,16 \pm 0,02$ \\
Pre-cocción & $\begin{array}{c}\text { Filete cocido } \\
\text { sin piel }\end{array}$ & $69,9 \pm 0,02$ & $19,4 \pm 0,1$ & $3,3 \pm 0,01$ & $1,45 \pm 0,01$ \\
Esterilización & $\begin{array}{c}\text { Conserva de } \\
\text { desmenuzado } \\
\text { de anchoveta }\end{array}$ & $75,1 \pm 0,1$ & $16,6 \pm 0,2$ & $3,1 \pm 00$ & $1,93 \pm 0,05$ \\
\hline
\end{tabular}

* Valores promedio de tres determinaciones.

Tabla 2. Histamina, $\mathrm{N}$ de bases volátiles totales y pH en 4 etapas del proceso de elaboración de la conserva "desmenuzado de anchoveta" *.

\begin{tabular}{ccccc}
\hline $\begin{array}{c}\text { Etapa del } \\
\text { proceso }\end{array}$ & Producto & $\begin{array}{c}\text { Histamina } \\
\text { p pm }\end{array}$ & $\begin{array}{c}\text { Nitrógeno Bases } \\
\text { volátiles totales } \\
\text { mg N \% }\end{array}$ & pH \\
\hline Recepción & $\begin{array}{c}\text { Anchoveta } \\
\text { entera cruda }\end{array}$ & $27,0 \pm 0,05$ & $2,25 \pm 00$ & $6,04 \pm 0,14$ \\
$\begin{array}{c}\text { Eliminación de } \\
\text { la piel }\end{array}$ & $\begin{array}{c}\text { Filete crudo sin } \\
\text { piel }\end{array}$ & $7,9 \pm 0,02$ & $5,75 \pm 00$ & $6,02 \pm 0,16$ \\
Precocción & $\begin{array}{c}\text { Filete cocido } \\
\text { sin piel }\end{array}$ & $1,10 \pm 0.02$ & $3,92 \pm 00$ & $6,11 \pm 0,25$ \\
Esterilización & $\begin{array}{c}\text { Conserva de } \\
\text { desmenuzado } \\
\text { de anchoveta }\end{array}$ & $2,20 \pm 0,02$ & $9,34 \pm 00$ & $6,11 \pm 0,25$ \\
\hline
\end{tabular}

*Valores promedio de tres determinaciones.

a casi el $30 \%$ de niños menores de cinco años ${ }^{(4)}$. El Instituto Tecnológico de la Producción (ITP) ha venido impulsando el desarrollo de nuevos productos como alternativas para un mejor uso de este recurso pesquero. En el estudio se han evaluado las características físicoquímicas y microbiológicas, con énfasis en el perfil de ácidos grasos en 4 etapas del proceso de elaboración de la conserva "desmenuzado de anchoveta".

\section{MATERIAL Y MÉTODOS}

\section{Muestra y diseño}

La muestra, constituida por $20 \mathrm{~kg}$ de anchoveta, cuya longitud y peso promedio fueron de $14,5 \mathrm{~cm}$ y $25,3 \mathrm{~g}$, respectivamente por individuo, fue proporcionada por el ITP, contenida en cajas y a temperatura entre $1^{\circ} \mathrm{C}$ y $3,8^{\circ} \mathrm{C}$.

Con un diseño experimental de un solo bloque, con tres repeticiones, se realizó el estudio en las instalaciones y laboratorios del ITP en noviembre 2012.

\section{Elaboración de la conserva "desmenuzado de anchoveta"}

Se siguió la tecnología y etapas estandarizadas por el ITP como sigue:

a) Recepción de la materia prima. La muestra se recibió enhielada. b) Corte de cabeza, cola y eviscerado. Colocándose nuevamente en caja con hielo.

c) Eliminación de la piel. Por fricción mediante movimientos rotatorios. Se colocó la anchoveta eviscerada, descabezada y sin cola en canastillas de material plástico, los que se sumergieron en agua a $85-90^{\circ} \mathrm{C}$ durante 15 segundos. Se aplicaron movimientos rotatorios que por fricción con la canastilla y entre las respectivas unidades de pescado eliminaron la piel; posteriormente las muestras se enjuagaron con chorro de agua fría.

d) Precocción. La anchoveta sin piel fue colocada en bandejas para ser pre-cocida en un cocinador continuo a temperatura de $90-95^{\circ} \mathrm{C}$ por 25 minutos. Al término, se dejó enfriar a temperatura ambiente.

e) Homogeneización. Los filetes precocidos, incluyendo la columna vertebral, fueron colocados en una mezcladora, para homogeneizar durante 20 segundos, agregando salmuera al 3\% para saborizar el desmenuzado de la anchoveta.

f) Envasado. En envases redondos de hojalata recubiertos y de $425 \mathrm{~g}$ de capacidad.

g) Esterilización. Luego de sellar los envases conteniendo el producto, se procedió a esterilizar en autoclave a $116^{\circ} \mathrm{C}$ por 90 minutos.

\section{Métodos analíticos}

\section{Análisis físico-químicos}

En muestras por triplicado se determinó la composición proximal (agua, proteínas totales, lípidos totales, minerales totales). Por otro lado, histamina, nitrógeno de bases volátiles totales (N-BVT) y perfil de ácidos grasos, se evaluaron en muestras por duplicado ${ }^{(5)}$. Los análisis se realizaron en el producto obtenido en las siguientes etapa-producto obtenido:

a) Recepción del pescado - anchoveta entera cruda con piel,

b) Eliminación de la piel - filete crudo sin piel,

c) Pre-cocción de los filetes - filete cocido sin piel,

d) Esterilización - conserva "desmenuzado de anchoveta" en agua y sal.

-Determinación de agua. Por gravimetría a $102^{\circ} \mathrm{C}$ en estufa con circulación de aire. 
Tabla 3, Perfil de ácidos grasos (g \% de lípidos) en cuatro etapas del proceso de elaboración de la conserva "desmenuzado de anchoveta"**

\begin{tabular}{|c|c|c|c|c|c|}
\hline Ácidos grasos & & $\begin{array}{c}\text { Recepción } \\
\text { anchoveta entera } \\
\text { cruda }\end{array}$ & $\begin{array}{l}\text { Eliminación de la } \\
\text { piel filete crudo } \\
\text { sin piel }\end{array}$ & $\begin{array}{l}\text { Precocción filete } \\
\text { cocido sin piel }\end{array}$ & $\begin{array}{c}\text { Esterilización } \\
\text { conserva de } \\
\text { desmenuzado de } \\
\text { anchoveta }\end{array}$ \\
\hline Mirístico & C 14:0 & 7 & 5,8 & 5,8 & 5,9 \\
\hline Pentadecanoico & C15:0 & 0,4 & 0,4 & 0,4 & 0,4 \\
\hline Palmítico & C16:0 & 17,5 & 18,7 & 18,6 & 18,6 \\
\hline Heptadecanoico & C17:0 & 0,4 & 0,4 & 0,4 & 0,4 \\
\hline Esteárico & C18:0 & 5,6 & 3,6 & 3,7 & 3,9 \\
\hline Araquídico & C20:0 & 0,2 & 0,2 & 0,2 & 0,2 \\
\hline A,G, saturados & & 31,1 & 29,1 & 29,2 & 29,5 \\
\hline Palmitoleico & C $16: 1$ & 7,9 & 6,3 & 6,4 & 6,6 \\
\hline Oleico & C $18: 1 \mathrm{n}-9$ & 7,8 & 6,4 & 6,3 & 6,4 \\
\hline Vacénico & C $18: 1 \mathrm{n}-7$ & 3,1 & 3,1 & 3,2 & 3,3 \\
\hline Eicosaenoico & C $20: 1 \mathrm{n}-9$ & 0,7 & 0,6 & 0,6 & 0,6 \\
\hline A,G, monoinsaturados & & 19,5 & 16,4 & 16,4 & 16,8 \\
\hline Linoleico & C $18: 2$ n-6 & 0,9 & 0,8 & 0,8 & 0,8 \\
\hline Gama linolénico & C $18: 3$ n-3 & 0,3 & 0,3 & 0,3 & 0,3 \\
\hline Alfa linolénico & C $18: 3 \mathrm{n}-3$ & 0,6 & 0,5 & 0,5 & 0,5 \\
\hline Estearidónico & C $18: 4 \mathrm{n}-3$ & 2,7 & 2,1 & 2,1 & 2,1 \\
\hline Eicosatrienoico & C $20: 3 \mathrm{n}-3$ & 0,9 & 1 & 1 & 1 \\
\hline Clupanodónico & C $22: 5 \mathrm{n}-3$ & 2,4 & 2,8 & 2,8 & 2,8 \\
\hline A,G, polinsaturados & & 6,9 & 6,7 & 6,7 & 6,7 \\
\hline Eicosapentaenoico (EPA) & C $20: 5 \mathrm{n}-3$ & 22 & 21,2 & 20,7 & 20,8 \\
\hline Docosahexaenoico (DHA) & C $22: 6 \mathrm{n}-3$ & 9,8 & 15,8 & 15,5 & 15,5 \\
\hline A,G, polinsaturados Omega-3 & & 31,7 & 37 & 36,2 & 36,2 \\
\hline
\end{tabular}

* Valores promedio de dos determinaciones.

-Determinación de lípidos totales. Método de Soxhlet utilizando éter etílico anhidro.

-Proteína total: Método Kjeldahl. El factor de conversión de $\mathrm{N}$ a proteína fue 6,25.

-Minerales totales: Por vía seca, mediante incineración en mufla a $500^{\circ} \mathrm{C}$.

-Nitrógeno de bases volátiles totales (N-BVT): Método Oficial de las Comunidades Europeas ${ }^{(5)}$, los resultados se expresan en $\mathrm{mg} \mathrm{N} / 100 \mathrm{~g}$ de muestra.

-Histamina: Método de Lerke y Laurence ${ }^{(5)}$. La histamina fue extraída por cromatografía de intercambio iónico y cuantificada con ftaldialdehido en el Espectroflurómetro Shimadzu RF-1501.

-pH. Método electrométrico, mediante potenciómetro.

-Perfil de ácidos grasos. Por cromatografía de gas-líquido.

Se empleó el cromatógrafo Perkin Elmer Autosystem XL, con detector de ionización de flama; columna Supelcowax-10 de sílice fundida, $30 \mathrm{~m}$ de longitud, $0,25 \mathrm{~mm}$ de diámetro interno y $0,25 \mu \mathrm{m}$ de espesor de película. El tiempo de análisis fue de 65 minutos en las siguientes condiciones operativas de temperatura: horno $160^{\circ} \mathrm{C}-230^{\circ} \mathrm{C}\left(1^{\circ} \mathrm{C} / \mathrm{min}\right)$; inyector: $250^{\circ} \mathrm{C}$; detector: $270^{\circ} \mathrm{C}$. Los resultados se expresan como\% de lípidos.

\section{Análisis microbiológicos}

Se realizaron en la materia prima (anchoveta entera cruda con piel) y en la conserva.

-Numeración de microorganismos aerobios mesófilos viables: Por el método de recuento en placa ${ }^{(6)}$.

-Numeración de Escherichia coli: Método del número más probable, incubando las muestras a $35^{\circ} \mathrm{C}$ durante 48 horas ${ }^{(6)}$.

-Numeración de Staphylococcus aureus: Empleando placas Petrifilm Staph ${ }^{(6)}$.

-Detección de Salmonella spp: En muestras de la anchoveta entera cruda y mediante el método de FDA ${ }^{(7)}$.

-Examen de esterilidad comercial: Según la FDA ${ }^{(8)}$.

\section{Análisis estadístico}

Se procesaron los datos mediante el programa SAS V.9.1.3. Se realizó el análisis de varianza y se aplicó 
el test de rango múltiple de Duncan para establecer las diferencias a un nivel $p<0,05$.

\section{RESULTADOS}

\section{Composición proximal}

El contenido de proteínas en anchoveta cruda entera fue de $18,4 \mathrm{~g} \%$ y disminuyó en la conserva ya esterilizada a $16,6 \mathrm{~g} \%$. El contenido en lípidos en la materia prima $(6,99 \mathrm{~g} \%)$ disminuyó a $2,1 \mathrm{~g} \%$ en la etapa de eliminación de la piel. Los valores de lípidos en la pre-cocción (3,3 g\%) prácticamente se mantienen en el producto esterilizado (3,1 g\%). El contenido de minerales totales experimentó una ligera concentración, de 1,33\% en anchoveta entera cruda a $1,93 \%$ en el producto final.

Estos datos se detallan en la tabla 1.

\section{Histamina, bases nitrogenadas totales y $\mathbf{p H}$}

Los niveles de histamina disminuyen a través de todo el proceso de elaboración de la conserva, de 27,0 ppm en la anchoveta cruda entera, a 2,2 ppm en la conserva "desmenuzado de anchoveta".

Las bases nitrogenadas se incrementaron de 2,25 mg N\% en anchoveta cruda entera, a 9,34 mg N\% en el producto esterilizado, es decir en la conserva.

En el $\mathrm{pH}$ no se observó variación.

Estos datos se detallan en la tabla 2.

\section{Perfil de ácidos grasos}

Por el contenido y por la variación del mismo, en la materia prima y en el producto terminado, sobresalen el ácido palmítico (de 17,5 a 18,6 g\%), y los ácidos de la serie omega 3 de cadena larga: el ácido eicosapentaenoico (EPA de 22 a 20,8 g\%) y ácido docosahexaenoico (DHA de 9,8 a 15,5 g\%).

En la etapa eliminación de la piel se observa que la mayoría de los ácidos grasos experimentan disminución en sus porcentajes. En la etapa de precocción, los porcentajes son básicamente iguales a los de la conserva, encontrándose que los ácidos grasos saturados y los monoinsaturados disminuyen en $1,6 \%$ (de $31,1 \%$ a $29,5 \%$ ) y en $2,7 \%$ (de $19,5 \%$ a $16,8 \%$ ), respectivamente.

Los contenidos de los ácidos gama linolénico, alfa linolénico, eicosatrienoico y el cuplanodónico, pertenecientes a la serie omega, permanecen prácticamente sin variación desde el inicio del proceso en la anchoveta entera cruda, hasta la obtención de la conserva. El ácido poliinsaturado omega-3, EPA, experimentó una reducción de o,8 g\% en la etapa de eliminación de la piel; el DHA, se incrementó en 5,7 g\% (de 9,8\% en anchoveta entera cruda a 15,8 g\% en el filete crudo y sin piel).

\section{Análisis microbiológicos}

En anchoveta cruda entera, el número de microorganismos aerobios mesófilos viables y la numeración de $E$. coli, y de $S$. aureus, fueron: $92 \times 10$ $\mathrm{UFC} / \mathrm{g} ;<3 \mathrm{NMP} / \mathrm{g} ; \mathrm{y}<10 \mathrm{UFC} / \mathrm{g} ;$ respectivamente. No se detectó Salmonella spp.

La prueba de esterilidad comercial indicó que la conserva "desmenuzado de anchoveta" fue comercialmente estéril.

\section{DISCUSIÓN}

La composición química de los peces varía aún entre individuos de la misma especie ${ }^{(9)}$. En el proceso de elaboración de la conserva "desmenuzado de anchoveta" se evidenció que la fracción lipídica es el componente que muestra la mayor variación en la etapa de retiro de la piel, puesto que disminuyó $4,89 \mathrm{~g} \%$ con respecto a la anchoveta entera. Esto se explica debido a que los depósitos de los lípidos están localizados en el tejido subcutáneo y los músculos del vientre ${ }^{(9)}$.

Histamina: La reducción en el contenido de histamina de $27 \mathrm{ppm}$ en anchoveta cruda entera a 7,9 ppm en filete sin piel, se debe principalmente a la eliminación de las vísceras. Este valor es muy inferior al indicado por la FDA ${ }^{(10)}$ para pescado crudo fresco (no más de 50 ppm) y está dentro de lo requerido por la norma Indecopi ${ }^{(11)}$ para anchoveta en conserva (no más de $10 \mathrm{mg} / 100 \mathrm{~g}$ ).

Nitrógeno de bases volátiles totales (N-BVT): Aunque el valor encontrado en la conserva $(9,34 \mathrm{mg}$ $\mathrm{N} \%$ ) fue superior con respecto al valor encontrado en la anchoveta cruda entera (2,25 mg N\%), estos niveles se encuentran dentro de los valores aceptados para músculo de pescado fresco (25-30 mg N/10o g) y para la conserva (40-45 mg N /100 g) durante la manufactura de productos enlatados ${ }^{(12)}$.

$\mathrm{pH}$ : No se registraron cambios corroborando que se trata de un producto de baja acidez y con buena capacidad amortiguadora.

Ácidos grasos poli insaturados omega-3: En la etapa de eliminación de la piel del pescado, el EPA disminuyó o,8\%; el contenido de DHA se incrementó en $5,3 \%$; lo que corrobora que los peces concentran 
estos ácidos grasos en la piel, en los músculos y en las vísceras ${ }^{(13)}$.

En las etapas de precocción y en la de esterilización dichos valores disminuyen en o, $4 \%$ y en $0,3 \%$, respectivamente, con relación a los contenidos en el filete crudo sin piel (tabla 3), indicando que estos tratamientos térmicos no afectan el contenido de ácidos grasos poli insaturados omega-3. Es pertinente indicar que Shirosky y col ${ }^{(14)}$ encontraron una reducción del $20 \%$ en el DHA y de $18 \%$ en el EPA después de una hora a $100^{\circ} \mathrm{C}$ en conserva de anchoveta; mientras que en conserva de caballa congelada encontraron menores porcentajes (DHA, $15 \%$ y EPA $13 \%$ ).

Los efectos benéficos a la salud humana atribuidos a los aceites marinos, se relacionan principalmente con el contenido de estos ácidos grasos poliinsaturados omega-3 y a su rol fisiológico ${ }^{(15-18)}$. En el organismo se sintetizan en forma limitada por lo que deben ser obtenidos a través de los alimentos. El contenido de EPA (20,8 g\%) y de DHA (15,5 g\%) encontrados es superior a lo reportado (18 a 32\%) por Pigot y Tukey ${ }^{(19)}$ e inferior al valor encontrado por Valenzuela ${ }^{(13)}$ en aceite de pescado ( $43 \%$ de EPA + DHA).

Según las recomendaciones de la Organización para la Agricultura y la Alimentación / Organización Mundial de la Salud (FAO/OMS), 22 gramos de la conserva de "desmenuzado de anchoveta", aportarían la ingesta diaria recomendada (0,25 g/día) de DHA+EPA para los sujetos adultos; y 41 gramos aportarían la ingesta de EPA (o,1 g/día) y DHA (o,2 g/día ) para la mujer embarazada o en periodo de lactancia ${ }^{(20)}$.

\section{CONCLUSIÓN}

Durante la elaboración de la conserva "desmenuzadodeanchoveta" en la etapa de eliminación de la piel, los ácidos grasos poliinsaturados omega -3 disminuyen.

La pre-cocción y esterilización, aplicados en la elaboración de la conserva no afectaron el contenido de los ácidos grasos poliinsaturados omega-3, EPA y DHA. DHA.

Este producto contiene $20,8 \%$ de EPA y $15,5 \%$ de

Los resultados de análisis físico-químicos y microbiológicos indicaron que la conserva "desmenuzado de anchoveta" cumplió con los requisitos de calidad.

\section{REFERENCIAS BIBLIOGRÁFICAS}

1. PRODUCE. Anuario Estadístico. Ministerio de la Producción. Lima, 2010. p. 19-25.

2. Krzeczkowski R. Fatty acids in raw and processed Alaska Pink shrimp. Journal of the American Oil Chemists Society 1970; 47(11):451-2.

3. Instituto Tecnológico Pesquero. Anchoveta para consumo humano directo. Instituto Tecnológico Pesquero-ITP. Lima, 2003. p. 36.

4. INEI/MINSA. Encuesta Demográfica y de Salud Familiar. Instituto Nacional de Estadística. Ministerio de Salud del Perú. Lima, 2012.

5. Instituto Tecnológico Pesquero. Manual de Laboratorio LABS-ITP-FQ-oo1-98.ITP. Instituto Tecnológico Pesquero-ITP. Lima, 1998.

6. Food and Drug Administration. Bacteriological Analytical Manual Online. Center for Food Safety \& Applied Nutrition. FDA. USA, 2001. p. 11. [En línea] Acceso 20 de mayo 2014. Disponible en http://www. efsan.fda.gov/ebamtoc.htlm

7. Food and Drug Administration. Bacteriological Analytical Manual Online. Center for Food Safety \& Applied Nutrition. FDA. USA, 2003. p. 19. [En línea] Acceso 20 de mayo 2014. Disponible en http://www.fda. gov/bbs/topics/

8. INDECOPI. Conservas en productos de la pesca. Control de esterilidad. $1^{\text {ra }}$ ed. Instituto Nacional de la Competencia y de la Propiedad Intelectual. Lima, 2010. p. 15 .

9. Huss H. El pescado fresco: su calidad y cambios en su calidad. Colección Pesca № 29. Roma, 1988. p. 202.

10. Food and Drug Administration. Fish and Fishery Products Hazard and Control Guidance, FDA. Department of Health and Human Services. Public Health Service. FDA. USA, 2011.

11. INDECOPI. Conservas de productos Pesqueros. Anchoveta en conserva. Norma Técnica Peruana NTP. Lima, 2005.

12. Aubourg S. Loss of quality during the manufacture of canned fish product. Food Sci Tech Int 2001; 7(3): 199-215.

13. Valenzuela A, Nieto S, Uauy R. Desafíos tecnológicos para evaluar ácidos grasos omega-3 poliinsaturados en aceites marinos de uso alimenticio y farmacológico. Aceites y Grasas 1993; 53-61.

14. Shirosky Z, Kolakowska A. Chemical and functional properties of food lipids. CRC Press. Florida, 2002.

15. Diaz-Arguelles V. Deficiencia de ácidos grasos esenciales en el feto y en el recién nacido pretérmino. Rev. Cubana Pediátrica 2001; 73(1): 43-50.

16. Gatica A. Acidos grasos EPA y DHA y su vital importancia en la Nutrición Humana. Indualimentos. Instituto de Nutrición y Tecnología de Alimentos (INTA). Universidad de Chile. Santiago de Chile, 2011. p. 58-6o. 
17. Gaete M, Atalah E, Araya J. Efecto de la suplementación de la dieta de la madre durante la lactancia con ácidos grasos omega 3 en la composición de los lípidos de la leche. Revista Chilena de Pediatría 2002; 73 (3): 239-47.

18. Valenzuela R, Tapia G, Gonzales M, Valenzuela A. Ácidos grasos omega-3 (EPA y DHA) y su aplicación en diversas situaciones clínicas. Rev Chil Nutr 2011; 38(3): 356-67.

19. Pigott G, Tucker R. Effect of technology on nutrition. Marcel Dekker. New York, 1990. p. 362.

20. FAO/WHO. Dietary Recomendations on total fat \& fatty acids. Expert consultation on fats and fatty acids in human nutrition. WHO. Geneva, 2008.
21. MINSA/DIGESA. Criterios microbiológicos de la calidad sanitaria e inocuidad para los alimentos y bebidas de consumo humano. NTS o71. MINSA / DIGESA - Vo1. Lima, 2008.

Manuscrito recibido el: 23/07/14

Aceptado para su publicación el: 04/o9/2014

\section{Correspondencia:}

Nombre: $\quad$ Eloisa M. Hernández Fernández

Dirección: Jr. Puno 1002- Lima 1 - Perú

e-mail: ehernandez@unmsm.edu.pe 